\title{
Movimento social ou reprodução dos cursinhos pré- vestibulares convencionais? Um estudo do Cursinho Popular Emancipa em Marabá, Pará
}

Lucas de Sousa Costa', Rigler Costa Aragão

\begin{abstract}
Resumo
Neste trabalho, buscamos analisar características do Cursinho Popular Emancipa na cidade de Marabá, Pará, e discutir a respeito deste movimento social colocando em questão a natureza de suas atividades, com o objetivo de encontrar resposta para a seguinte pergunta, "O referido Cursinho é um movimento social emancipatório ou apenas reproduz os cursinhos pré-vestibulares convencionais?". Este trabalho torna-se relevante à medida que coloca em discussão um tema importante de interesse dos movimentos que se denominam "movimentos de educação popular", assim como faz parte das publicações iniciais acerca da dinâmica da Rede Emancipa, Movimento de Cursinhos Populares em Marabá. Por meio de pesquisa bibliográfica e estudo de caso foram coletadas informações, entrevistas, discussão e dados para que este trabalho se configurasse, e fosse fundamentado. A pesquisa realizada permite concluir que o Cursinho Popular Emancipa Zé Cláudio e Maria do Espírito Santo não só apenas auxilia os estudantes na preparação para vestibulares e Enem, mas também proporciona formação crítica, voltada para a emancipação e organização da luta pela conquista de direitos, dessa forma, em partes, reproduz a dinâmica de um cursinho pré-vestibular convencional, mas busca (e tem isso como objetivo e práxis), a emancipação dos envolvidos (alunos e professores) pela educação popular.
\end{abstract}

\section{Palavras-chave}

Educação. Cursinho Popular. Movimento Social.

1. Especialista em Metodologia do Ensino de Ciências pela Faculdade Mantenense dos Vales Gerais, Pará, Brasil; professor voluntário da Rede Emancipa, Marabá, Pará, Brasil. E-mail: lucascostamba@gmail.com.

2. Mestre em Geofísica pela Universidade Federal do Pará, Brasil; professor da Universidade Federal do Sul e Sudeste do Pará, Campus de Marabá, Brasil. E-mail: rigler@unifesspa.edu.br. 


\title{
Social movement or reproduction of pre-university conventional courses? A study of the Popular Course Emancipa in Marabá, State of Pará, Brazil
}

Lucas de Sousa Costa*, Rigler Costa Aragão**

\begin{abstract}
In this work, we try to analyze the characteristics of the Popular Course Emancipa in the city of Marabá, State of Pará, Brazil, and discuss this social movement by questioning the nature of its activities to find an answer to the following question: "this course is an emancipatory social movement or does it only reproduce the conventional pre-vestibular courses?" This work becomes relevant as it brings into discussion an important topic of interest of the movements that are called "popular education movements", as it is part of the initial publications about the dynamics of the emancipation networking, popular courses movement in Marabá. Through the bibliographic research and case study, information, interviews, discussion and data were collected so that this work could be configured, and thus be supported. The research made it possible to conclude that the Emancipa Zé Cláudio and Maria do Espírito Santo popular course not only assists students in the preparation for the university entrance exams and Enem, but also provides critical training, aiming the emancipation and organization of the struggle for the conquest of rights, in this way, in parts it reproduces the dynamics of a conventional pre-university course, but seeks (and has this as its goal and praxis), the emancipation of those involved (students and teachers) through popular education.
\end{abstract}

\section{Keywords}

Education. Popular Course. Social Movement.

\footnotetext{
* Specialist in Science Teaching Methodology, Faculdade Mantenense dos Vales Gerais, State of Pará, Brazil; volunteer teacher of the Emancipa Popular Course, Marabá, State of Pará, Brazil. E-mail: Iucascostamba@gmail. com.

* Master of Geophysics, Federal University of Pará, State of Pará, Brazil; professor at the Federal University of Southern and Southeastern Pará, State of Pará, Brazil. E-mail: rigler@unifesspa.edu.br
} 


\section{Introdução}

De modo geral, movimentos sociais conceitualmente possuem referência às ações coletivas de um grupo, que, organizado, objetiva alcançar mudanças na sociedade através do embate político, com ações orientadas de acordo com seus valores e ideologias em um contexto da sociedade dividida em classes sociais. Apresentam-se como movimentos feministas, ecológicos, contra a fome, pela reforma agrária, dentre outros. A Rede Emancipa - Movimento Social de Educação Popular - também faz parte dessa gama de movimentos que busca intervir para uma sociedade mais justa. O movimento configura-se na construção de cursinhos prévestibulares em lugares cedidos como igrejas, associações de moradores, universidades e até mesmo como projetos de extensão universitária, devido a uma de suas características como cursinho: ser desenvolvido através da ação voluntária de pessoas que compartilham do mesmo desejo, qual seja, o de universidade pública, democrática e popular.

O Cursinho Popular Emancipa: Movimento de Educação Popular (CPE) foi implantado em Marabá, no sudeste do Pará, no ano de 2012, como resultado da organização e iniciativa da juventude participante de movimentos estudantis na Universidade Federal do Pará (UFPA), no campus de Marabá, atualmente Universidade Federal do Sul e Sudeste do Pará (UNIFESSPA). Hoje, configura-se como um programa de extensão da UNIFESSPA que buscou se institucionalizar devido à precariedade de recursos materiais. O Cursinho Popular Emancipa, possui como objetivos: defender a educação pública, gratuita e de qualidade em todos os níveis; lutar pelo livre acesso à educação; auxiliar na organização da juventude nas lutas sociais pela conquista dos direitos de cidadania. Busca uma alternativa de educação que não se fundamenta apenas a atender aos conteúdos programáticos de vestibulares e ensino médio, mas proporcionar, por meio da educação popular, uma nova perspectiva de ensino transformador pautado na ideia de Freire (1994) de que a pessoa conscientizada tem uma compreensão diferente da história e de seu papel nela; recusa-se a acomodar-se, mobiliza-se, organiza-se para mudar o mundo.

O CPE busca centralizar suas ações na possibilidade da construção a partir da educação, de uma sociedade nova, marcada pela ação cotidiana de lutas dos estudantes e trabalhadores para que haja a transformação e construção social. Para isso é necessário que haja a organização e o engajamento popular:

\footnotetext{
Assim como o opressor, para oprimir, precisa de uma teoria da ação opressora, os oprimidos, para libertarem-se, necessitam igualmente de uma teoria de sua ação [...]. O povo, por sua vez, enquanto esmagado e oprimido, introjetando o opressor, não pode, sozinho, constituir a teoria de sua ação libertadora. (FREIRE, 2014, p. 183).
}

Um dos propósitos do CPE é inserir os alunos nas universidades públicas, por meio da preparação para os vestibulares e o Exame Nacional do Ensino Médio (Enem). Contudo não se restringe a isso. Busca-se, por meio da educação popular, desenvolver a consciência social, política e cultural dos alunos e voluntários. A educação popular torna-se, então, um caminho de educação para a liberdade e autonomia na construção de sujeitos ativos e transformadores da realidade em que estão inseridos, pois acreditamos, assim como Paulo Freire, que a luta de classe pode fortalecer-se, tornar-se expressiva e, assim, conquistar suas reivindicações.

As chamadas minorias, por exemplo, precisam 
reconhecer que, no fundo, elas são a maioria. O caminho para assumir-se como maioria está em trabalhar as semelhanças entre si e não só as diferenças e assim criar a unidade na diversidade, fora da qual não vejo como aperfeiçoar-se e até como construir-se uma democracia substantiva, radical. (FREIRE, 1994, p. 154).

A organização da juventude, nesse sentido, é de fundamental importância para alcançar mudanças significativas na sociedade. A educação popular, fundamentada na concepção freiriana de educação libertadora dos sujeitos, desenvolve-se no CPE a partir das atividades de reflexão sobre a sociedade, levando à discussão temas propostos como transversais em todas as disciplinas e também discutidos na formação política dos estudantes.

Muito mais que uma vaga no banco da universidade pública, queremos que os alunos passem a refletir sobre a sociedade e sobre todos os mecanismos de opressão que a envolvem. Neste sentido, concordamos com Freire ao dizer que seremos críticos verdadeiros se vivermos a plenitude da práxis, o que exige um pensar constante, que não pode ser negado às massas populares, se o objeto visado é a libertação (FREIRE, 2014, p. 176). A teoria e a ação refletida é o que tornam a educação popular no CPE um mecanismo de transformação social.

A estratégia de pesquisa empregada foi o estudo de caso. Segundo Laville e Dione (1999), a vantagem dela está na possibilidade de aprofundamento que oferece, posto que

os recursos se veem concentrados no caso visado, não estando o estudo submetido às restrições ligadas a comparação do caso com outros casos. Ao longo da pesquisa, o pesquisador pode, pois, mostrar-se mais criativo, mais imaginativo; tem mais tempo de adaptar seus instrumentos, modificar sua abordagem para explorar elementos imprevistos, precisar alguns detalhes e construir uma compreensão do caso que leve em conta tudo isso, pois ele não mais está atrelado a um protocolo de pesquisa que deveria permanecer o mais imutável possível. (LAVILLE; DIONE, 1999, p. 155).

A opção pela escolha está ligada ao objeto de estudo que é amplo e dinâmico, abrange o estudo do CPE, em Marabá-PA, e a relação dicotômica entre a emancipação e o assistencialismo, que atinge alunos e professores, como um caso a ser explorado, e ainda a possibilidade de oferecer maior amplitude no estudo, favorecendo condições de utilização de uma variedade de dados coletados. Baseada no objetivo proposto, em que serão analisados dados de fontes diversas, a pesquisa deverá se enquadrar na abordagem qualitativa, pois, segundo Triviños (1990), permitirá o estudo do fenômeno de forma integrada. As informações levantadas não merecerão análise estatística, mas uma análise dos fatores a partir da relação com os indivíduos para compreensão do fenômeno posto, portanto a abordagem qualitativa.

Ainda, levando em consideração o objetivo proposto e a temática escolhida, as características apontam para uma pesquisa exploratória. De acordo com Gil (2002), esse tipo de pesquisa é adequado quando a temática ainda é pouco explorada, permitindo uma visão geral sobre o fenômeno em estudo e aumentando a familiaridade do pesquisador com o ambiente para estudos futuros e mais precisos.

Deverá ser utilizada ainda a pesquisa descritiva, cujo conceito de aplicabilidade se enquadra às necessidades do objetivo. Gil (2002) define que as pesquisas descritivas têm como objetivo primordial a descrição das características de determinada população ou fenômeno ou, então, o estabelecimento de relações entre variáveis, sendo fundamental na caracterização do cursinho popular e, mais especificamente, o que se deseja pesquisar.

Os sujeitos alvos da pesquisa foram contatados levando em consideração o grau 
de participação no movimento, proximidade e envolvimento com a temática a ser estudada. Os instrumentos e técnicas utilizadas para a coleta de informações foram: entrevista semiestruturada, questionário para levantamento de informações no cursinho popular.

\section{Educação popular}

Como referência para definir educação popular, faremosas reflexõesà luz do pensamento de Paulo Freire, que caracteriza a educação popular no livro Pedagogia do Oprimido como "educação libertadora", educação voltada para o povo e para a emancipação dos oprimidos.

Dentre as várias referências que Freire faz acerca de uma educação libertadora dos sujeitos, podemos entender que a educação popular está diretamente ligada a um processo educativo que estimule o pensar autêntico, que não se deixa emaranhar pelas visões parciais da realidade, buscando sempre os nexos que prendem um ponto a outro, ou um problema a outro, propondo aos educandos ter uma visão mais crítica do mundo (FREIRE, 2014). É uma educação contrária à educação "bancária", pois, ao invés de alienar, fazer depósitos, domesticar, dificultar o pensar autêntico, é uma educação que visa à libertação autêntica, que é a humanização em processo. Não se trata de algo que se deposita nos homens, não é apenas uma palavra a mais, vazia, mistificante, se trata de ser práxis, que implica a ação e reflexão dos homens sobre o mundo para transformá-lo.

Para desenvolver a "pedagogia da libertação", Freire ressalta que é necessária uma educação problematizadora, capaz de romper com os esquemas verticais característicos da educação bancária, construída através do diálogo. Nesse processo, o educador não é o que apenas educa, mas o que, enquanto educa, é educado dialogando com o educando, que ao ser educado também educa, nesse processo, ambos crescem juntos (FREIRE, 2014).
Já agora ninguém educa ninguém, como tampouco ninguém se educa a si mesmo: os homens se educam e comunhão, mediatizado pelo mundo. Mediatizados pelos objetos cognoscíveis que, na prática "bancária", são possuídos pelo educador que os descreve ou os deposita nos educandos passivos. (FREIRE, 2014, p. 79).

\section{Cursinhos populares e a Rede Emancipa}

Há muito conhecemos os cursinhos pré-vestibulares, são aqueles que têm como objetivo preparar os alunos para aprovação nos exames vestibulares, cuja dinâmica, geralmente, consiste em intensificar a "aprendizagem" dos conteúdos mais abordados nos vestibulares, e são muito caros. Muitos alunos, após concluírem o ensino médio, procuram por esses cursinhos com o intuito de se prepararem melhor para tais exames e para o Enem, que se tornou uma das principais formas de ingresso nas universidades públicas brasileiras.

Mendes (2011) buscou desvelar a ideia de cursinho popular dentro da dinâmica da Rede Emancipa e, a partir de sua pesquisa, percebemos dois dos elementos que o caracterizam: primeiro, o fato de ele não visar o lucro. De acordo com a autora, "se identifica o caráter popular do cursinho no fato de ele não visar o lucro ou de ser gratuito. Com isso, em primeiro plano, o que caracterizaria um cursinho popular é o elemento material, permitir que as classes populares o frequentem" (MENDES, 2011, p. 90). Entretanto, "ser gratuito não é condição suficiente para ser popular, há diferentes elementos necessários para tal, um deles seria não estar voltado exclusivamente para o vestibular" (MENDES, 2011, p. 90), de onde decorre o segundo elemento que o caracteriza: não estar voltado exclusivamente para o vestibular. Assim, a proposta do cursinho popular, ainda segundo a autora, seria, então, a de permitir que os alunos "saiam da casca 
do ovo", procurando descobrir o que há por trás desse mundo, a partir das próprias ideias.

Na tentativa de possibilitar uma formação complementar para os alunos oriundos das escolas públicas que querem concorrer a uma vaga nas universidades públicas e, ao mesmo tempo, tentar colocar em prática uma educação popular, em 2008, iniciam-se os primeiros CPE em São Paulo, estabelecendo configuração e organização de movimento social.

É no ano de 2008, após [...] experiências inconclusas, que são fundados três cursinhos que dão dinâmicas à Rede Emancipa até hoje. O primeiro deles foi o Cursinho Chico Mendes, em Itapevi. Quase que no mesmo tempo, foi criado o Cursinho Paulo Freire, no bairro do Tatuapé, zona Leste de São Paulo. Poucos meses depois, é inaugurado o Cursinho Popular do Butantã, bairro da zona oeste da capital. (MENDES, 2011, p. 67-87).

Desde então, esse movimento social tem expandido e se apresenta em cinco estados brasileiros: Rio de Janeiro, São Paulo, Rio Grande do Sul, Pará, Minas Gerais e Distrito Federal.

\section{O Cursinho Popular Emancipa, em Marabá- PA, e o educador popular}

Desde sua fundação, em 2012, cerca de 1.600 alunos já passaram pelo CPE. É importante ressaltar que há grande evasão por motivos diversos, dentre eles o fato de funcionar aos sábados e domingos e algumas pessoas não se adaptarem a isso; alguns alunos não possuírem condições financeiras para custear passagens, incompatibilidade de horário com o trabalho ou serviço temporário ou até mesmo por conta de alguns não simpatizarem com o projeto. Atualmente o CPE funciona nas dependências da Universidade Federal do Sul e Sudeste do Pará (UNIFESSPA), com aulas somente nos finais de semana. Conta com 18 (dezoito) bolsistas, vinculados à Pró-
Reitoria de Extensão da UNIFESSPA, que recebem importante apoio institucionalmente.

Estima-se que 120 ex-alunos do CPE ingressaram em cursos de nível superior em diversas instituições públicas e particulares no Brasil. Esses dados são imprecisos, pois as aulas no cursinho se encerram em data que antecede a prova do Enem, e somente cerca de três meses depois é que o resultado das primeiras chamadas de aprovados e outras mais chamadas ocorrem, e durante esse período, muitas vezes, perde-se o contato com os alunos, daí não se poder fornecer dados mais precisos.

O CPE conta com a ação voluntária, em sua maioria de estudantes de graduação que ministram aulas, porém, com menos frequência, participam também professores da rede municipal e estadual de ensino e, em algumas situações, professores da UNIFESSPA. Mais de 60 colaboradores já participaram ativamente do projeto, e há uma grande rotatividade entre eles, já que muitos são acadêmicos bolsistas e voluntários, não residentes em Marabá, que voltam para suas cidades de origem após a conclusão de seus cursos na universidade; outros conseguem empregos e há também os que não simpatizam com o projeto. Sobre os estudantes de graduação que constroem o movimento, muitos se identificam com ele e passam a participar ativamente das atividades do CPE, aqui chamados de "militantes". Outros entram por curiosidade ou em busca de experiência profissional ou apenas para adquirir carga horária para as atividades complementares exigidas por seus cursos de graduação. Esses passam pouco tempo, não se identificam com a proposta do projeto, alcançam seus objetivos e se vão.

Buscamos constantemente superar a pedagogia tradicional, excluindo a verticalização dos processos que envolvem aluno e professor. Concordamos com Gohn (2010) quando nos alerta que, na educação não formal, há a figura do educador social, mas o grande educador é 
o outro, aquele com quem interagimos ou nos integramos, lembrando, ainda, que a finalidade desse modo de educar é abrir janelas de conhecimento sobre o mundo que circunda os indivíduos e suas relações sociais.

É por meio do processo de horizontalidade, do diálogo, da troca de experiências entre alunos e professores que buscamos construir caminhos para uma metodologia ou didática de ensino (que ainda está para ser construída com as muitas outras experiências que virão) que tornará sólida a educação popular no CPE. Não podemos definir um método ou didática, pois esse modo de educar é construído com o resultado do processo voltado para os interesses e as necessidades dos que participam, e assim "prepara, formando e produzindo saberes nos que interagem nesse processo (alunos/professores), educando para a civilidade, oposição à barbárie, ao egoísmo, ao individualismo etc" (GOHN, 2010, p. 16).

Freire (2011) também ressalta a importância da relação harmoniosa entre aluno e professor para a construção de práticas pedagógicas que resultarão em uma educação libertadora, "o pensar certo que supera o ingênuo tem que ser reproduzido pelo próprio aprendiz em comunhão com o professor formador. [...] através da reflexão sobre a prática, a curiosidade ingênua, percebendo-se como tal, se vá tornando crítica" (FREIRE, 2011, p. 39-40).

Uma das tarefas mais alegres de um educador, segundo Alves (2015) é provocar nos seus alunos a experiência do espanto. Segundo ele, um aluno espantado é um aluno pensante, o que remete à ideia do perfil de professor que buscamos ser, um educador capaz de tornar suas aulas um momento de aprendizagem crítica e aproveitar o conteúdo de ensino para provocar um momento de reflexão sobre o que se está discutindo. Há muito conhecimento "pronto e acabado" nos livros e na internet, e é necessário que nós, professores, sejamos capazes de dar sentido ao que se vê na sala de aula, buscando utilizar a experiência cotidiana do educando como contexto real da problemática. É necessário fazer com que o aluno reconheça e associe o que está nos livros com as situações encontradas no seu bairro, na sua cidade, ao seu redor. Dessa forma, eles serão capazes de compreender os problemas, buscar possíveis encaminhamentos de soluções e, ainda, organizarem-se com a população na tomada de decisões. Ainda, nesse sentido, Freire (1996, p. 33) destaca:

Por que não aproveitar a experiência que têm os alunos de viver em áreas da cidade descuidadas pelo poder público para discutir, por exemplo, a poluição dos riachos e dos córregos e os baixos níveis de bem-estar das populações, os lixões e os riscos que oferecem à saúde das gentes.

Corroborando com autores citados, acreditamos que o processo de aprendizagem é construído a partir das trocas de experiências, nas quais alunos e professores constroem e compartilham aprendizagem reciprocamente.

\section{Emancipação e assistencialismo no Cursinho Popular Emancipa Zé Cláudio e Maria do Espírito Santo, em Marabá-PA}

De acordo com Mendes (2011), considerando as desigualdades perpetradas pelo modo de produção capitalista, torna-se difícil afirmar, categoricamente, se uma determinada experiência educacional se configura como sendo de emancipação ou de assistencialismo, entretanto, segundo a autora, é possível que, no transcorrer de suas experiências, os cursinhos populares "estejam focando sua atuação política em prover 'igualdade de oportunidades', o que, de certa forma, reforça a discussão de que é o esforço e mérito de cada estudante que o coloca na universidade" (MENDES, 2011, p. 67). A autora ressalta que, mesmo com o 
objetivo de se constituir como experiência emancipadora, o cursinho popular esbarra no fato de a Universidade ser encarada como elemento capaz de mudar as condições materiais dos jovens (ganharem melhores salários), que estão lá por essa razão e não para que "se emancipem". Desta feita, "o foco na emancipação, se há um tempo é uma resposta direcionada exatamente aos que não vão passar no vestibular (a grande maioria), precisa ser construída enquanto respostas coletivas ao anseio individual de melhorar suas condições de vida" (MENDES, 2011, p. 67-68).

A partir de pesquisas realizadas por Mendes (2011), observamos que os cursinhos populares buscam ser espaço de formação emancipadora, contudo esbarram em questões pertinentes a uma sociedade capitalista, na qual a natureza de suas atividades acaba tendo como fim o sucesso individual, e não o coletivo, e a capacitação para o trabalho e não somente formação cidadã crítica emancipatória.

A partir de agora, caracterizaremos o objeto de estudo desse trabalho, buscando discutir e identificar elementos que evidenciem a emancipação ou o assistencialismo no CPE em Marabá-PA, levantando posições acerca do seguinte questionamento: "O Cursinho Popular Emancipa, em Marabá-PA, é um movimento social emancipatório ou apenas reproduz os cursinhos pré-vestibulares convencionais?".

Essa discussão foi realizada através de entrevistas feitas com 5 (cinco) professores, sendo que 4 (quatro) deles participam ativamente das atividades do cursinho, e um não desenvolve mais atividades, mas teve importante participação na sua fundação. Os cinco serão identificados neste texto como P1, P2, P3, P4 e P5.

O primeiro entrevistado (P1) é professor aposentado do magistério superior. O segundo professor (P2) participou da fundação do cursinho (na época era graduando em matemática, mas mudou de cidade depois que concluiu a graduação). O terceiro (P3) estuda licenciatura em Letras. O quarto (P4) estuda licenciatura em Ciências Sociais. $\mathrm{O}$ quinto (P5) é estudante do curso de licenciatura e bacharelado em Geografia. Com exceção de P2 todos os outros entrevistados ministram aulas no CPE.

Algumas falas ilustram o que os professores pensam sobre o tema. O entrevistado P1, propõe a reflexão:

No que somos diferentes de um cursinho convencional? Por enquanto só temos vontade e não cobramos taxas. Tem algo a mais diferente? Quando eu for dar uma aula de Química vou publicar: eu não quero datashow! Eu não quero nem quadro e nem pincéis! Eu quero conversar com os alunos e poder perguntar muito. Quero saber quais são as metas e objetivos deles, quero ajudálos a elucidar esses objetivos, torná-los menos nebulosos. E o programa do Enem? Se tiver impresso em um papel macio, poderemos usá-lo no banheiro. (P1).

De acordo com o entrevistado, para se caracterizar como um movimento de educação para a emancipação, as atividades do CPE, em Marabá, ainda estão longe de se configurarem a essa finalidade. Para ele, é mais importanteajudar os estudantes a alcançarem seus objetivos, e a grade curricular do Enem é pouco interessante para uma educação cujo alvo é a emancipação.

Uma possível saída para nós é caminharmos no sentido de levar o Emancipa para os bairros, para junto da população. Reforço, alfabetização, teatro popular, música etc. são meios de interagirmos com a população. Por enquanto estamos somente na vontade e não existe nada que garanta que seremos um movimento social emancipatório daqui a alguns anos. (P1).

O entrevistado aponta alternativas para as atividades do cursinho, possibilidades do movimento se aproximar ainda mais das classes populares na tentativa de desenvolver atividades 
que possam estar ainda mais voltadas para a emancipação e não atividades cujo objetivo é a preparação para o Enem. Porém, diz não haver certeza de o cursinho se tornar um movimento social emancipatório no futuro. Dessa forma, o professor (P1) caracteriza-o como uma atividade genuinamente assistencialista.

Para o professor (P2),

A emancipação dentro do Cursinho Emancipa ocorre nos momentos de formação para os alunos e para os professores, nas intervenções que o Cursinho Emancipa participa, nos momentos de debates que acontecem dentro das salas, e inserção de disciplinas como Direitos Humanos e Artes. Como assistencialismo, no aspecto que temos de suprir o papel da Escola Pública, de termos que seguir a ementa do ENEM e obedecer ao padrão que a escola pública segue. (P2).

De forma objetiva, o entrevistado caracteriza a natureza do cursinho como sendo de assistencialismo e de emancipação. Para ele, o movimento proporciona espaços de formação diferente da escola pública, como a disciplina voltada para os Direitos Humanos, os seminários, as rodas de conversa com temas relevantes. Assim, para P2, o cursinho em partes reproduz a dinâmica dos cursinhos convencionais ao preparar os alunos para os vestibulares e Enem e desenvolve a emancipação ao proporcionar formação voltada para o desenvolvimento crítico dos alunos.

O entrevistado P3 caracteriza da seguinte forma:

Sinceramente, não há como comparar o Emancipa Marabá com os cursinhos convencionais. Fato que a gente trabalha muito mais a conscientização dos nossos alunos, o que não acontece nos cursinhos convencionais. No entanto, cabe a reflexão que a gente ainda peca em alguns aspectos, que é a preocupação muito grande com o "conteudismo" do Enem. Mas, ainda assim, conseguimos ter uma educação muito mais libertadora e "conscientizadora" que qualquer cursinho convencional. (P3).

Para esse professor, o CPE desenvolve sim uma educação libertadora, portanto configurase como um movimento para a emancipação, pois busca a conscientização dos alunos, mas reconhece que há a preocupação em ensinar conteúdos do Enem, o que assemelha o CPE, neste aspecto, aos cursinhos convencionais, porém, ainda assim, suas atividades estão mais voltadas para a emancipação.

$\mathrm{O}$ quarto professor entrevistado (P4) assim se posiciona:

\begin{abstract}
Movimento social é uma tentativa de emancipação, pelo menos na práxis. Minha opinião é essa. O caminho ainda é longo. Mas o espírito é esperançoso. O que difere é que há (no grau de existência) um espírito (vontade) de direcionamento para uma emancipação, e há uma consciência do que é educação e onde queremos chegar. Não visamos apenas benefício de chegar ao ensino superior ou ser transmissor de conhecimento, vamos para o âmbito de esclarecimento e emancipação. (P4).
\end{abstract}

Fica claro para P4 que o CPE não é um movimento emancipatório consolidado, mas, os esforços são reunidos no sentido de um dia ele ter essa configuração.

Por último, o professor P5, relata:

Buscamos, através de atividades diferenciadas que não acontecem em cursinhos convencionais, utilizar um modelo de educação libertadora e horizontal, onde todos os conhecimentos sejam utilizados, sem desvalorizar os conhecimentos de mundo dos alunos. Ou seja, não há supremacia de conhecimento por parte de quem está ministrando aulas, o que há é uma contribuição, por parte dos docentes, para aqueles que estão ali precisando de suporte. Sobre as atividades diferenciadas, destaco formações políticas a professores e alunos, gerando debates sobre alguns temas sociais na tentativa de esclarecer sobre os ideais de cada caso e, através disso, fazê-los enxergar 
a realidade e assim não reproduzir diversas formas de preconceitos dentro do Emancipa. (P5).

De acordo com as descrições, observamos que para P5 há uma diferença do cursinho popular para os cursinhos convencionais, e as principais são as formações políticas, a horizontalidade do processo de ensino-aprendizagem, a discussão sobre problemas sociais, ou seja, a "fuga" dos conteúdos programáticos dos vestibulares e Enem, o que caracteriza o CPE como um movimento emancipatório. As práticas educativas desenvolvidas no CPE têm sido pautadas em reflexões críticas sobre a sociedade, e a troca de conhecimento entre os envolvidos é fundamental para esse processo. Os alunos e voluntários participam com frequência de debates, rodas de conversa, formação política e manifestações, quebrando o estereótipo de que cursinho é lugar de aprender "macetes" de assuntos para o vestibular. A participação em atos públicos também tem sido ação desenvolvida pelos integrantes do cursinho; atos nos quais tem sido levantada a bandeira da educação pública e de qualidade para todos.

Os alunos do projeto adquirem conhecimentos que não só os prepararam para os vestibulares e Enem. Por meio da educação popular, eles recebem formação que visa à preparação para transformação da realidade social e busca desenvolver a consciência crítica dosalunos no sentido de os tornarem autônomos, agentes transformadores da realidade social. Por meio das atividades do projeto, esses jovens, tantos os alunos do cursinho quanto os estudantes de licenciaturas que compõem o projeto, passam a se organizar melhor em busca de seus ideais.

As atividades do CPE muito se assemelham às dos cursinhos pré-vestibulares convencionais, principalmente quando essas são voltadas para alcançar um de seus objetivos: a preparação dos alunos para os vestibulares e Enem. Em contrapartida, outros elementos o caracterizam como um projeto que desenvolve atividades para a emancipação, tais como a organização, a divisão do trabalho, a gratuidade, a intencionalidade da execução de atividades voltadas para a elevação do pensamento crítico, ou seja, uma formação não exclusiva para a preparação para os vestibulares e Enem, a luta pela justiça social, mais especificamente a luta pela garantia de vagas nas universidades públicas para as classes populares.

\section{Considerações finais}

O Cursinho Popular Emancipa em Marabá-PA tem proporcionado aos alunos oportunidade de se prepararem para os vestibulares e, sobretudo desenvolverem sua capacidade de pensar, tornando-os sujeitos capazes de intervir e transformar a sociedade, auxiliando também, na potencialização da organização do trabalho coletivo e social.

O CPE tem se mostrado não apenas um instrumento de assistencialismo, mas buscado proporcionar reflexão aos jovens para que eles sejam capazes de atuar na sociedade, nas lutas sociais e no trabalho. Reconhecemos que não são objetivos fáceis de alcançar, principalmente diante da atual conjuntura social, política e econômica em que nos encontramos, porém, parafraseando Freire, "ai de nós se deixarmos de sonhar sonhos possíveis".

A pesquisa evidenciou a divergência de pensamento acerca da natureza das atividades do cursinho. Pudemos observar que há participantes que identificam o projeto como majoritariamente assistencialista, pouco se diferenciando de um cursinho convencional; outros o identificam como pertencendo a duas naturezas, uma vez que, devido à função do cursinho de preparar para o vestibular, torna-se, em partes, uma atividade de reprodução dos cursinhos convencionais.

O tema torna-se inconcluso, pela dinâmica do cursinho pesquisado, dos atores 
e da sociedade em que ele está inserido, contudo, compreendemos que existem concepções diferentes sobre emancipação e assistencialismo nessa dinâmica: enquanto há os que presumem que uma educação emancipadora ainda está muito distante, há os que acreditam que essa educação já está sendo desenvolvida nas atividades do CPE, porém não apartada do assistencialismo pela função de preparar os alunos para os convencionais exames vestibulares e o Enem, ou seja, de acordo com as entrevistas, podemos dizer que o assistencialismo e a emancipação estão sendo desenvolvidos mutualmente no Cursinho Popular Emancipa, em Marabá, e que ele caminha, ainda que a passos lentos, para desenvolver com maior expressão, atividades emancipatórias.

\section{Referências}

ALVES, R. Conversa sobre educação. Campinas: Verus, 2010. 130 p.

FREIRE, P. Pedagogia da autonomia: saberes necessários à prática docente. São Paulo: Paz e Terra, 2011. 253 p.

Cartas a Cristina. Rio de janeiro: Paz e Terra, 1994. 334 p.

. Pedagogia da esperança: um reencontro com a pedagogia do oprimido. 3 ed. Rio de Janeiro: Paz e Terra, 1994. 245 p.

Pedagogia do oprimido. 58. ed. Rio de Janeiro: Paz e Terra, 2014. 107 p.

GIL, A. C. Como elaborar projetos de pesquisa. 4. ed. São Paulo: Atlas, 2002. 175 p.

GOHN, M. G. Educação não formal e o educador social: atuação no desenvolvimento de projetos sociais. São Paulo: Cortez, 2010. 103 p.

LAVILLE, C.; DIONNE, J. A construção do saber: manual de metodologia da pesquisa em ciências humanas. Belo Horizonte: Editora da UFMG, 1999. 340 p.

MENDES, M. T. Inclusão ou emancipação: um estudo do cursinho popular Chico Mendes. 2011. 118 f. Dissertação (Mestrado em Educação) - Faculdade de Educação, Universidade Federal do Rio Grande do Sul, Rio Grande do Sul, 2011.

TRIVIÑOS, A. N. S. Introdução à pesquisa em ciências sociais: a pesquisa qualitativa em educação. São Paulo: Atlas, 1990. 175 p.

Submetido em 10 de janeiro de 2018.

Aprovado em 24 de abril de 2018. 